\title{
Adams-Stokes syndrome caused by paroxysmal third-degree atrioventricular block
}

\author{
G. Jensen, B. Sigurd, J. Meibom, and E. Sandøe \\ From Medical Department B, Rigshospitalet, University of Copenhagen, Denmark
}

Among 170 patients with Adams-Stokes syndrome, the majority had sinus rhythm between attacks. Clinical and electrocardiographic features of 67 patients in whom syncope was caused by paroxysmal third-degree atrioventricular block are discussed. The patients had normal pulse rates between attacks, their cerebral symptoms were usually not accompanied by cardiac symptoms, and 25 per cent had no symptoms suggesting heart disease. However, in 83 per cent the electrocardiogram showed constantly interventricular conduction disturbances and $7 I$ per cent episodically atrioventricular conduction disturbances. It appears that the diagnosis, which otherwise may be missed, may be greatly facilitated by electrocardiograms.

The variability and complexity of the QRS patterns suggest a development of third-degree AV block in the form of an 'additive' block. The final lesion in the complete block may vary both in location, proximall distal, in the conduction system, and in degree of involvement of the pacemaking tissue. Both factors may contribute to an alternation between episodes of third-degree $A V$ block with and without escape rhythm, and correspondingly without and with Adams-Stokes attacks.

Implantation of an artificial pacemaker is life saving and allows most of the patients who have suffered attacks of unconsciousness, due to episodes of ventricular asystole, to return to normal life (Harris et al., 1965; Cosby and Bilitch, 1972). This therapeutic achievement has made the identification of patients with Adams-Stokes attacks a matter of practical clinical importance.

The diagnosis is straightforward if the fainting spells occur in connexion with chronic third-degree AV block, i.e. in patients with slow heart rate as first described by Adams (1827) and Stokes (1846). However, Adams-Stokes attacks may also occur in patients with sinus rhythm and a correspondingly normal heart rate. The attacks may in these cases be caused by paroxysmal ventricular fibrillation (Harris et al., 1965; Sandøe and Flensted-Jensen, 1969; Wennevold and Sandøe, 1970), sinoatrial block (Müller and Finkelstein, 1966), or paroxysmal third-degree AV block complicated by ventricular asystole (Stokes, 1947).

The aim of this paper is to evaluate the prevalence of the latter type of cardiac syncope, to work out criteria for its proper identification, and to elucidate its aetiology and nature.

Received 25 September 1972.

\section{Patients}

By 1972 a total of 170 patients with Adams-Stokes attacks had had a pacemaker implanted at the University Hospital of Copenhagen. One hundred and six patients were in sinus rhythm at the time of the implantation of pacemaker, while 64 had third-degree AV block. The cause of syncope in 106 patients with sinus rhythm was sinoatrial block in 39 , and intermittent AV block complicated by ventricular asystole in 67 .

The latter 67 patients form the basis of the present study. In 62 patients, electrocardiograms during fainting spells showed third-degree AV block and ventricular asystole which lasted for 5 to 60 seconds. In the remaining 5 patients an electrocardiogram was not recorded during fainting spells, but a diagnosis of Adams-Stokes disease was made likely by registration of periods of third-degree AV block not however followed by ventricular asystole because of the immediate establishment of a stable escape rhythm. The diagnosis was finally supported by the effect of treatment, as the syncopal attacks stopped after the implantation of an adequately functioning pacemaker (follow-up time 6 months to 7 years).

Permanent pacemaker implantation was only performed in patients considered to have a chronic, intermittent tendency to cardiac syncope. Consequently, the present group of patients does not include cases of AV conduction disturbances due to acute myocardial infarction, drug intoxication, or electrolyte disturbances. 


\section{Results}

The male to female ratio was $2.5: \mathrm{I}$. The average age of men at their first syncope was approximately 65 , and of women 75 (Fig. I). The presence of additional heart disease is shown in Fig. 2. Twenty-four patients had arteriosclerotic heart disease with a typical history of stress-provoked angina pectoris or of an earlier acute myocardial infarction. Four patients presented signs of significant aortic valvular disease and 3 of mitral valvular disease. Two patients had arterial hypertension. The group miscellaneous includes 3 patients who had had rheumatic

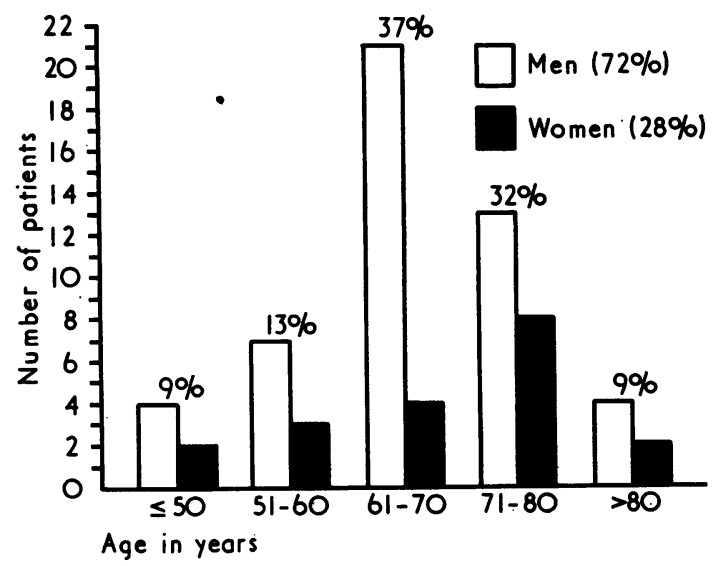

FIG. I Age at first attack and sex: 67 patients with Adams-Stokes attacks caused by paroxysmal thirddegree atrioventricular block.

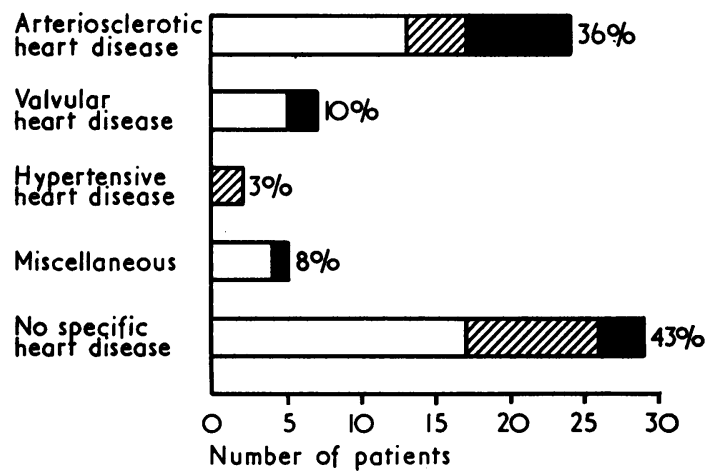

Cardiac volume $<600 \mathrm{ml} / \mathrm{m}^{2}$
Cordiac volume $\geq 600 \mathrm{ml} / \mathrm{m}^{2}$
Cardiac volume $\geq 600 \mathrm{ml} / \mathrm{m}^{2}+$ congestive heart foilure

FIG. 2 Additional heart disease and heart size: 67 patients with Adams-Stokes attacks caused by paroxysmal third-degree atrioventricular block. fever (II, 3I, and 48 years before the onset of syncope), one who had had acute trichinosis two years before, and one patient with chronic polymyositis. Twenty-nine patients did not present signs of any specific heart disease, but because of heart enlargement (and in 3 cases congestive failure) 12 can be classified as cases of cardiomyopathy. The remaining 17 patients presented no signs of cardiac disease, with the exception of fainting spells and conduction defects as described later.

Most fainting attacks started suddenly and unexpectedly, without preceding sensation of disturbed cardiac function in the form of irregular, slow or fast heart beats, dyspnoea, or chest pain. Episodes of unconsciousness of 'minutes' duration' were reported in all cases, and $17 \mathrm{had}$, on one or several occasions, been unconscious for more than 30 minutes. Alternating with fainting, I4 patients had had numerous episodes of black-out or temporary dizziness. The time between the first attack of fainting and the establishment of a diagnosis of Adams-Stokes disease exceeded one year in 24 patients, whereas 23 patients had had more than Io syncopal attacks before the diagnosis was made (Table I).

Fig. 3 shows AV conduction disturbances observed during sinus rhythm. Normal AV conduction was observed on one or several occasions in 47 patients (70\%). First-degree AV block, i.e. PR exceeding $0.2 \mathrm{I}$ sec without dropped beats, was recorded in 21 patients $(31 \%)$. AV block of Wenckebach type was inconsistently observed in 4 patients $(6 \%) .2$ : I AV block was observed in 34 patients $(51 \%)$ and 3: $1 \mathrm{AV}$ block in one patient in periods of varying duration. In 8 patients $(12 \%)$ the $2: I$ AV block was accompanied by $P R$ prolongation, which remained constant within each episode, but often changed from one episode to another.

Fig. 4 shows the incidence of interventricular conduction disturbances during sinus rhythm. Normal interventricular conduction, i.e. normal QRS con-

TABLE I Number of attacks of syncope and time from first attack to implantation of pacemaker in 67 patients with Adams-Stokes attacks caused by paroxysmal third-degree $A V$ block

\begin{tabular}{llllll}
\hline $\begin{array}{lllll}\text { No. of } \\
\text { attacks }\end{array}$ & \multicolumn{4}{l}{$\begin{array}{l}\text { First attack - pacemaker implantation } \\
\text { (time in days) }\end{array}$} & Total \\
\cline { 2 - 5 } & $<7$ & $7-30$ & $31-365$ & $>365$ & \\
I-2 & 3 & 5 & 4 & 3 & 15 \\
$3-10$ & 0 & 8 & II & 10 & 29 \\
$>10$ & I & 2 & 6 & 14 & 23 \\
\hline Total & 4 & I5 & 21 & 27 & 67 \\
\hline
\end{tabular}




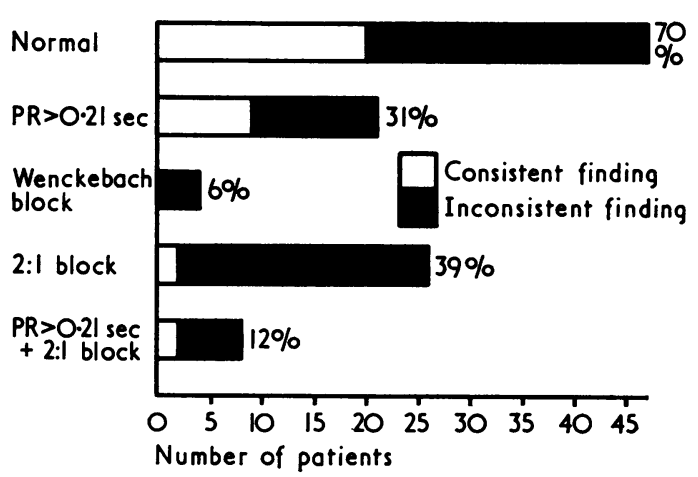

FIG. 3 Atrioventricular conduction disturbances during sinus rhythm: 67 patients with Adams-Stokes attacks caused by paroxysmal third-degree atrioventricular block. The sum of the percentages exceeds 100 as several atrioventricular conduction disturbances were observed in some of the patients.

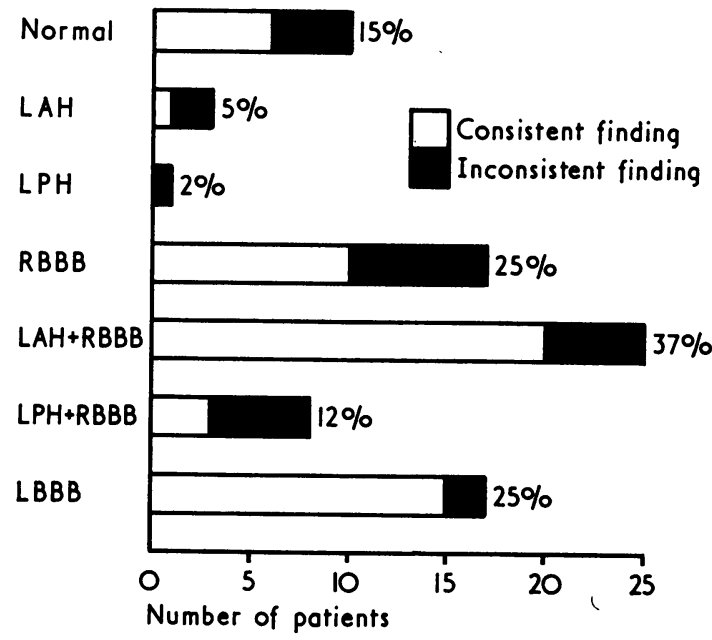

FIG. 4 Interventricular conduction disturbances during sinus rhythm: 67 patients with Adams-Stokes attacks caused by paroxysmal third-degree atrioventricular block. Left anterior hemiblock $(L A H)$, left posterior hemiblock (LPH), right bundle-branch block (RBBB), and left bundle-branch block (LBBB). The sum of the percentages exceeds roo as several interventricular conduction disturbances were observed in some of the patients.

figuration was observed in Io patients ( $15 \%$ ) on one or several occasions, and found consistent in 6 patients $(9 \%)$. Right bundle-branch block combined with left anterior hemiblock was recorded in 25 patients $(37 \%)$, in most cases as a stable pattern.
Right and left bundle-branch block were each present in 17 patients $(25 \%)$, the former being less stable, and, if changing, often alternating with left anterior hemiblock + right bundle-branch block. Right bundle-branch block combined with left posterior hemiblock was recorded in 8 patients ( $12 \%$ ), usually as an unstable QRS pattern. Left bundle-branch block was a stable pattern, only alternating with right bundle-branch block in 2 cases.

Atrioventricular and interventricular conduction disturbances were frequently found in combination and the different $\mathrm{AV}$ conduction disturbances were evenly distributed among the different groups of interventricular conduction defects. One patient only had consistently neither AV nor interventricular conduction disturbances during sinus rhythm. Sinus node dysfunction in the form of atrial fibrillation and flutter was observed in 6 patients ( $9 \%$ ).

No correlation between electrocardiographic abnormalities, sex, age, or additional heart disease could be found.

Episodes of third-degree AV block followed by immediate establishment of an escape rhythm and consequently not resulting in fainting were recorded in a total of 54 patients. Fig. 5 outlines characteristics of the observed escape rhythms. Unchanged QRS pattern compared to the one observed in sinus rhythm was recorded in 24 patients. Changed QRS pattern was seen in 30 patients.

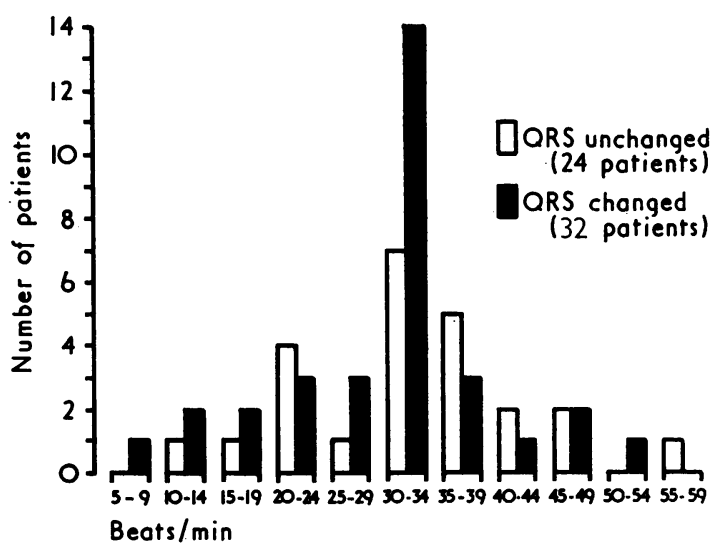

FIG. 5 Heart rate and $Q R S$ configuration in escape rhythm: 54 patients with episodes of third-degree atrioventricular block and escape rhythm. The white columns indicate unchanged $Q R S$ pattern compared to the one seen in sinus rhythm, the black columns correspondingly changed QRS pattern. Two patients appear in both groups, as both changed and unchanged escape rhythm were observed. 
Regardless of the QRS configuration, the heart rates were between 20 beats a minute and 50 beats a minute, the median value being approximately 35 beats a minute.

\section{Discussion}

Adams-Stokes attacks are recognized as a frequent complication of chronic third-degree AV block, but may also develop in third-degree AV block of paroxysmal type, i.e. in patients who most of the time between attacks have normal heart rate and sinus rhythm (Stokes, 1947). The present study gives a ratio of chronic to paroxysmal third-degree AV block of 64/67 in I3I patients with AdamsStokes attacks caused by AV block.

Little is known about the natural history of this apparently not uncommon type of Adams-Stokes disease. Clinical and aetiological features of the present series are the same as reported in chronic third-degree AV block with Adams-Stokes attacks (Penton, Miller, and Levine, 1956; Rowe and White, 1958) a finding which supports the presumption that the two conductions have the same grave prognosis (Johansson, 196I).

The identification of patients with syncope due to paroxysmal third-degree AV block may be diffcult. The pulse rate between attacks is normal, the cerebral symptoms are usually neither preceded nor followed by cardiac symptoms, and, finally, about 25 per cent of the patients do not present signs or symptoms of heart disease except the syncopal attacks. However, abnormalities are present on the electrocardiogram in most cases. Stokes (1947) found bundle-branch block in 18 out of 31 patients with sinus rhythm, and prolonged $P Q$ in Io of the remaining patients. In the present series interventricular conduction disturbances were observed on one or several occasions in 9I per cent (Fig. 4), and AV conduction disturbances in 72 per cent (Fig. 3). One patient only showed neither interventricular nor atrioventricular conduction disturbances.

PR prolongation, often observed combined with QRS patterns of the bundle-branch or hemiblock type, may be due either to slow conduction in the not fully blocked remaining part of the ventricular conduction system or to slow conduction in the AV node or bundle of His (Rosen et al., 197I).

Table 2 is an attempt to classify the paroxysmal third-degree AV blocks in our series according to the trifascicular concept of the ventricular conduction system (Rosenbaum et al., 1970). The outcome is one minor group of patients with main bundle and two major groups of patients with bilateral bundle-branch and tri-fascicular third-degree AV block. The variability and complexity of the QRS
TABLE 2 Type of third-degree $A V$ block

\begin{tabular}{|c|c|c|}
\hline $\begin{array}{l}\text { Interventricular IV } \\
\text { conduction defect(s) in } \\
\text { sinus rhythm }\end{array}$ & $\begin{array}{l}\text { No. of } \\
\text { patients }\end{array}$ & $\begin{array}{l}\text { Supposed type of third- } \\
\text { degree } A V \text { block }\end{array}$ \\
\hline None & $6\} 6$ & Main bundle ( $9 \%)$ \\
\hline $\begin{array}{l}\text { Right bundle-branch } \\
\text { block only } \\
\text { Left bundle-branch } \\
\text { block only } \\
\text { Right }+ \text { left bundle- } \\
\text { branch block }\end{array}$ & $\left.\begin{array}{l}13 \\
15\end{array}\right\} 30$ & Bilateral bundle $(45 \%)$ \\
\hline $\begin{array}{l}\text { Left anterior hemi- } \\
\text { block only } \\
\text { Left anterior hemi- } \\
\text { block + right bundle- } \\
\text { branch block } \\
\text { Left posterior hemi- } \\
\text { block }+ \text { right bundle- } \\
\text { branch block } \\
\text { Left anterior + left pos- } \\
\text { terior hemiblock }+ \\
\text { right bundle-branch } \\
\text { block }\end{array}$ & $5\}^{23} 31$ & Tri-fascicular $(46 \%)$ \\
\hline
\end{tabular}

patterns point towards a development of thirddegree $\mathrm{AV}$ block in the form of an 'additive' block caused by multiple lesions scattered through the ventricular conduction system, parallel to what has been observed in chronic third-degree AV block (Davies and Harris, 1969; Lenègre, 1966).

Between the Adams-Stokes attacks, episodes of third-degree AV block followed by immediate establishment of an escape rhythm were recorded in most patients. In the escape rhythm a grouping corresponding to a proximal/distal location of the final component in the third-degree AV block might have been expected in junctional rhythm with fairly high rate and unchanged QRS pattern, and in ventricular rhythm with low rate and changed, or in some cases, unchanged, QRS pattern (Lopez, I968). No such grouping was found (Fig. 5), which suggests that the QRS configuration is influenced by other factors than a proximal/distal location of the block in the conduction system. One such factor might be a varying involvement of the pacemaking tissue which, according to the concept of 'preferential pathways', would result in different QRS patterns (Sherf and James, I969).

In conclusion, the final lesion in the third-degree AV block may vary from time to time in both location, i.e. proximal/distal, in the conduction system, and in degree of involvement of the pacemaking tissue. Both factors may contribute to an alternation between episodes of third-degree AV block with or 
without escape rhythm and correspondingly without or with Adams-Stokes attacks.

\section{References}

Adams, R. (1827). Cases of diseases of the heart, accompanied with pathological observations. Dublin Hospital Reports, 4, 353.

Cosby, R. S., and Bilitch, M. (1972). Heart Block. McGrawHill, New York.

Davies, M., and Harris, A. (1969). Pathological basis of primary heart block. British Heart fournal, 31, 219.

Harris, A., Bluestone, R., Busby, E., Davies, G., Leatham, A., Siddons, H., and Sowton, E. (1965). The management of heart block. British Heart fournal, 27, 469.

Johansson, B. W. (196I). Adams-Stokes syndrome. A review and follow-up study of forty-two cases. American fournal of Cardiology, 8, 76.

Lenègre, J. (1966). Bilateral bundle branch block. Cardiologia, 48, 134 .

Lopez, J. F. (1968). Electrocardiographic findings in patients with complete atrioventricular block. British Heart fournal, 30, 20.

Müller, O. F., and Finkelstein, D. (1966). Adams-Stokes syndrome due to sinoatrial block. American fournal of Cardiology, 17, 433 .

Penton, G. B., Miller, H., and Levine, S. A. (1956). Some clinical features of complete heart block. Circulation, 13, 801 .

Rosen, K. M., Rahimtoola, S. H., Chuquimia, R., Loeb, H. S., and Gunnar, R. M. (197I). Electrophysiological signifi- cance of first degree atrioventricular block with intraventricular conduction disturbance. Circulation, 43, 491.

Rosenbaum, M. B., Elizari, M. V., Kretz, A., and Taratuto, A. L. (1970). Anatomical basis of A-V conduction disturbances. In Symposium on Cardiac Arrhythmias, p. 147. Ed. by E. Sandøe, E. Flensted-Jensen, and K. H. Olesen. AB Astra, Södertälje, Sweden.

Rowe, J. C., and White, P. D. (1958). Complete heart block: a follow-up study. Annals of Internal Medicine, 49, 260.

Sandøe, E., and Flensted-Jensen, E. (1969). Adams-Stokes seizures in patients with attacks of both tachy- and bradycardia, a therapeutical challenge. Acta Medica Scandinavica, 186, III.

Sherf, L., and James, T. N. (1969). A new electrocardiographic concept: synchronized sinoventricular conduction. Diseases of the Chest, 55, 127.

Stokes, W. (1846). Observations on some cases of permanently slow pulse. Dublin Quarterly fournal of Medical Science, 2, 73.

Stokes, W. (1947). Paroxysmal heart block in bundle branch block. British Heart fournal, 9, 267.

Wennevold, A., and Sandøe, E. (I970). Paroxysmal malignant arrhythmias in childhood and adolescence. In Symposium on Cardiac Arrhythmias, p. 767. Ed. by E. Sandøe, E. Flensted-Jensen, and K. H. Olesen. AB Astra, Södertälje, Sweden.

Requests for reprints to Dr. E. Sandøe, Medical Department B, Rigshospitalet, 9 Blegdamsvej, Copenhagen $\varnothing$, Denmark. 